\title{
Õhtumaine maagia
}

\section{Mõned märksõnad selle ajaloo kohta}

\section{Dieter Harmening}

Sõna 'maagia' on tuletatud ladinakeelsest terminist magia (kreeka keeles mageía, iraani-vanapärsia vormina magu[s]); see sõna on suguluses ka kreeka mõistetega méchos, mechané, gooti sõnaga mahts, saksa Macht ning tähendab indogermaani verbitüves *magh 'suutma, saama, aitama'.

Ladina nimisõna magus (kreeka sõnast mágos) märkis algselt meediumitest preestrite kasti liiget, hiljem lisandus tähendus 'unenägude seletaja, nõiduja' ja pejoratiivse värvinguga 'maag, pettur'. Niisiis tähendas sõna 'maagia' algselt maagide õpetust, see tähendab üleloomulike jõudude ja väe omandamise kunsti, hiljem aga juba ka halvustavalt petturlikku nõiakunsti. 1 Nendes keeleajaloost lähtuvates seletustes on ära märgitud kolm õhtumaise maagiamõiste kujunemisloo olulist aspekti:

1. maagia kui teadus ja teadmine looduses ja loomisprotsessis peituvatest jumalikest jõududest («magia naturalis»),

2. maagia kui nimetatud teadmise praktiline tarvitamine ettekuulutustes, oraaklites ja nõidumisel,

3. petturlik nõiakunst; viimane hinnang kujutas endast ühtlasi tõhusat pidepunkti kristlikule demoniseerimisele.

1. Oma töös Aurora philosophorum kirjutas Paracelsus (umbes 1493-1541): «Paljud mõistsid maagide, kaldealaste, pärslaste ja egiptlaste salajast tarkust mitte ainult üksipulgi, vaid oskasid seda ka salajaselt ja avalikult pruukida, ja see pole täninigi lõpetatud» $\underline{\underline{2}}$ ning tõendab seega, et Õhtumaades on levinud nii teoreetilised käsitlused kui praktiline tegelemine maagidele omaseks peetud teadmistega. Cicero jaoks oli magi näol tegemist «pärslaste hulgast pärineva õpetlase või targaga.» Vanas Testamendis räägitakse kaldea soost ettekuulutajatest ja tähetarkadest ${ }^{4}$ ning ka Uue Testamendi kolm kuningat olid maagid ja Hommikumaa targad. ${ }^{5}$ Kreeka filosoofid ${ }^{6}$ nagu näiteks Empedokles (5. saj eKr) ${ }^{7}$, Demokritos (5.-4. saj eKr), ${ }^{8}$ Pythagoras (6. saj eKr), ${ }^{9}$ Protagoras (5. saj eKr) ${ }^{\mathbf{1 0}}$ olid väidetavalt tutvunud Pärsia maagide õpetustega, $\underline{\underline{11}}$ Aristoteles (umbes $25 \mathrm{eKr}$ kuni $50 \mathrm{pKr}$ ) peab seda õpetust katseks seletada kõike eksisteerivat kõrgeimast printsiibist lähtuvalt. $\underline{\mathbf{1 2}}$ Erilisteks autoriteetideks tunnistatakse maagid hilisantiigist pärit uusplatonismis. Iamblichos (umbes $275-330 \mathrm{pKr}$ ) 13 üritab «assüürlaste põliseid dogmasid», st nende õpetust, «täpselt ja tõelevastavalt edasi anda», 14 Philon (384-322 eKr) iseloomustab seda kui «vaatlemise teadust», «mis püüab looduse poolt loodut arusaadavate selgituste abil mõistetavaks teha.» $1 \mathbf{1 5}$

Õhtumaise maagia-mõiste arengule mõjusid tugevasti uusplatoonikute demonoloogilised ja kosmoloogilised arutlused. $\underline{\mathbf{1 6}}$ Nende lähtepunktiks oli teooria hierarhiliselt korraldatud kosmosest, milles Plotinose järgi (205-270) tekib kõrgeimast printsiibist lähtuva ajatu ja lõputu kiirgamise (ehk emanatsiooni) tõttu noeetiline substants (intellekt, vaim), sellest omakorda psüühiline substants, mis on aluseks mateeriale. Hiljem hakati neid emanatsiooni erinevaid astmeid käsitlema konkreetsete jõududena, mida kujutati hilisantiigi ingli- ja deemoniusu mõjustusel inimesekujulistena. Iamblichose pakutud astmeline kosmos on sellele protsessile ainult tõenduseks. Tema töös leiab uusplatonistlik kosmoloogia hilisantiigile omase sünkretismi läbi kreekalik-orientaalse polüteismi vaimus väljundi, mida toetavad elemendid Pytha- 
gorase arvukombinatsioonidest ning millele lisandub maagiline mõõde. «Kõrgemaid» kiirgusi lähendatakse «madalamatele» teatavate vahepealsete olendite kaasabil. Mida «kõrgemal» need vahendustegevuses osalevad instantsid paiknevad, seda rohkem sarnanevad nad oma loomult jumalate ja deemonitega, mida «madalamal» need on, seda lähedasemad on need psüühilis-spirituaalsele aspektile. Nimetatud vahepealsete olendite hord jaguneb vastavalt kosmilise ligitõmbejõu reeglitele ridadesse («seiraí»).

Eriti detailselt on ülaltoodud süsteemi kujutanud Proklos (410-485): 17 hierarhiliselt korraldatud kosmoseelementide «kettides» avaldab teatud tähejumala jõud ja olemus mõju kõigele allpool olevale, kusjuures kaugemal see mõju järk-järgult väheneb. Uusplatonistlik kosmoloogiline teoloogia ning sellega kaasnev kriitika on oma ajaloolise kujunemise käigus mõjustanud ka tänapäevase looduskäsitluse vormumist. Lõppude lõpuks võlgneme tänu just sellele pärandile ning sellega kaasnenud mitmekülgsetele arutlustele kaasaegse looduskontseptsiooni ettevalmistamise eest. Samas aga põhjustas see õpetus oma fantastiliste demonoloogiliste konstruktsioonide tõttu ka eksijärelduste tegemist, mis paiskasid kogu Euroopa nõiaprotsesside kaosesse. Mitmesugused traditsioonilised voolud ning protsessid seovad neid uusaja alguses aset leidnud sündmusi hilisantiigi teoloogilis-kosmoloogiliste ideedega - kristliku demonoloogia ja ebausuteooria väljakujunemine, keskaegsed mõttevahetused loomuliku maagia («magia naturalis») lubatavuse üle, Araabia allikad hilisantiigi loodusfilosoofia kohta koos selle edasiarendustega ning uusplatonistliku loodusteoloogia retseptsioon renessansi ajal. $\underline{18}$

Alfons Kastiiliast laskis 1256. aastal tõlkida araabia keelest ladina keelde raamatu pealkirjaga Picatrix $\underline{19}$ ning tõi sellega Euroopa avalikkuse ette muudatused, mille Araabia vaimusuurused olid sisse viinud uusplatonistlikku kosmoloogiasse. Araabia kogumiku maagilisloodusfilosoofilist suunda ei rõhuta mitte ainult Johannes Hartlieb (enne 1410-1468), 20 vaid sellele viidatakse ka Petrus von Abano (1257-1316), 1 Johannes Trithemiuse (1462-1516)른 ja Johannes Weieri (1515-1588)른 töödes, eriti selgelt ilmneb see aga retseptsioonis, mis saab raamatule osaks Heinrich Cornelius Agrippa von Nettesheimi (1486-1535) teoses De occulta philosophia. ${ }^{24}$ Kuigi üldiselt täiesti uusplatonistlike ideede vaimus kirjutatud, demütologiseerib Picatrix kosmilise ligitõmbejõu read suures osas vaid astroloogilisteks kettideks: planeedid liiguvad oma trajektooril, mis viib neid kord ülespoole kinnistähtede kogumite (tähtkujude) suunas, kord jälle alla maise maailma suunas, tuues endaga ülevalt kaasa taevalikke mõjusid ja jõude. Astroloogiline maagia, mida Picatrix'is kirjeldatakse, püüab leida vahendeid nendest maale perioodiliselt mõju avaldavatest kõrgematest jõududest osasaamiseks. Selleks üritatakse vastavad mõjujõud koondada mingisse planeetide valda kuuluvasse substraati, näiteks talismani. Võimalikult paljude samale planeedile omaste elementide ühendamise teel loodetakse moodustada spetsiaalne ruum (umbes nagu akumulaator), milles tähtede jõud ja mõju saaksid avalduda. Niisiis võib nentida, et «talismanide toime tuleneb nende seotusest taevakehadega». Õigupoolest oli looduslikest faktoritest («agens naturale») tingitud tähtede mõju Õhtumaades juba ammugi tuntud, Picatrix tutvustas aga lisaks puhtdemonoloogiliselt tõlgendatavale maagiale veel teist suunda - nimelt astroloogiliselt mõjustatud ridu ehk teisisõnu, astroloogilistele mõjudele (seega ettemääratusele) alluva looduse ideed.

Uus arutelu ja kriitika maagilis-astroloogilise kausaalsuse üle tärkas renessansi filosoofias, eriti florentiinlikus platonismis. $\underline{25}$ Humanistlik liikumine juhindus platonistlike ideede käsitlemisel hilisantiigi pärandist ning kohtus seetõttu esmalt õpetuse uusplatonistliku vormiga. Kokkupuutel uusplatonismi filosoofilise mõistemaailmaga tuli humanistidel muidugi ühtlasi tegemist teha ka maagilis-astroloogilise kosmoloogiaga. Keskajalgi lähtuti veel tugevalt 
astroloogilise kausaalsuse seisukohast, kuid täieliku astroloogilise ettemääratuse idee oli kaotanud oma varasema tähtsuse vähemalt niikauaks, kuni domineeris usk tähtedest kõrgemal seisvasse jumalikku valitsusse (astra regunt homines, sed regit astra deus, 'tähed valitsevad inimese üle, kuid jumal valitseb tähtede üle'). «Kuid mida kaugemale edasi liigutakse, seda rohkem jõutakse äratundmisele, et just maiste huvide ja ilmaliku hariduse esiletõusmine suurendab kalduvust astroloogiliste põhiõpetuste poole.) $\geqslant \mathbf{2 6}$ Tõtt-öelda praktiliselt mõjustas vääramatu maagilis-astroloogilise kausaalsuse idee renessansi looduskäsitlust visalt kuni 17. sajandini välja.

Marsilio Ficino (1433-1499) käsitlus De triplici vita ${ }^{27}$ astroloogilise süsteemi kohta näitab aga juba selgelt, kui suur oli soov selles kindlakskujunenud põhjuse ja tagajärje ahelas teha ruumi vabaduse mõistele. Kuna Ficino kirjutab üldiselt veel täiesti emanatsiooniõpetuse vaimus ja on Picatrix'i eeskujul veendunud ülemise ja alumise sfääri kiirguste olemasolus, arvab ta inimesi alluvat nende sünniplaneetide mõjule. Sealjuures olevat aga inimesel vabadus vastavale planeedile omaste võimaluste ja mõjude piires vabalt valikuid teha ning sellest lähtuvalt ennast arendada ja täiustada. $\underline{28}$ Ficino esitab ka uue maagia-mõiste definitsiooni, seostades maagiat armastusega: mõlemad põhinevad ligitõmbel (attractio), mida «üks ese teatud olemusliku suguluse tõttu avaldab teisele. [---] Sellest tuleneb armastus ning armastusest vastastikune ligitõmme. See ongi tõeline maagia. $\rangle^{29}$

Giovanni Pico della Mirandola (1463-1494), samuti üks tähtsaid Florenze akadeemia esindajaid, oli esimene, kes avaldas maagilis-astroloogilise maailmapildi põhitõdedele veendunud vastupanu..$^{\mathbf{3 0}}$ Erinevalt Ficinost, kes otsis inimese iseseisvusele avaldumisvõimalust astroloogiliselt ettemääratud kosmose piirides, eitas Pico della Mirandola ideed kõige toimuva astroloogilisest ettemääratusest täiesti. Maailma nähtusi ei saavat aduda mingite oletuste või ideede põhjal, vaid ainult konkreetsetest põhjustest lähtuvalt. Peamist tekkepõhjust kõigele, mida taevas annab, ei tarvitse aga kaugelt otsida, kuna see ei tulene millestki muust kui valgusest ja soojusest, niisiis ammutuntud, hõlpsasti tõestatavatest mõjuritest. Ainult need vahendavad taevaseid mõjutusi ning on ühtlasi meediumiks, mille kaudu geograafiliselt üksteisest kaugel eemal olevad objektid dünaamiliselt ühendatakse. ${ }^{31}$ Hiljem liitusid Johannes Kepler (1571-1630) ja Isaak Newton (1643-1727) Pico della Mirandola poolt kirjeldatud «vera causa», tõelise põhjuse ideega. Uusplatonistlike kosmilise ligitõmbe ridade ja Picatrix'i maagilis-astroloogiliste ahelate kontekstis osutab Pico üleskutse vajadusele näidata kõigepealt, et järjepidevad üleminekud ühest mõjust teiseks on üldse olemas, ning siis need seadusena formuleerida - alles seejärel saab rääkida kausaalsete seoste olemasolust.

2. Juba antiigis tunti mõistet 'maagia' ka üldisemas tähenduses. Diogenes Laertius (3. saj $\mathrm{pKr}$ ) võrdles maage India gümnosofistide ja keldi druiididega ning laiendas seega mõiste kehtivuspiirkonda. $\underline{32}$ Laertiuse järgi tuleb maagia loojaks pidada Zoroastrit (Zarathustra); hiljem pani Isidor Sevillast (umbes 560-633) aluse sama oletuse levimisele keskaja mõtlejate seas. ${ }^{33}$ Isidor kasutab sõnapaari 'maagiline kunst' kokkuvõtvalt ettekuulutuste, oraaklivõtete ja surnute väljakutsumise kohta. Hugo St-Victorist (11. saj lõpp -1411) kasutab seda kõiki ennustuslikke ja maagilisi kunste hõlmava koondmõistena ${ }^{34}$ ning siit peale hakkab maagiamõiste oma ulatuse poolest kattuma ladina superstitio ehk 'ebausuga'. Sealjuures pärineb aga keskaegne (ja hilisemgi) maagiaterminoloogia suures osas antiigist, kust see on Augustinuse ja Sevilla Isidori kaudu kristlikku kirjandusse üle kandunud, näiteks nekromantia, geomantia, hüdromantia, aeromantia, püromantia, astroloogia, divinatsioon, inkantatsioon (loits), auspiitsid, augur (preester, kes lindude käitumise järgi kuulutab jumala tahet), haruspeks (preester, kes ohvriloomade sisikonna jm põhjal ennustab tulevikku), matemaatika, horoskoop jt. .35 Juhtudel, kui taheti muid valdkondi nõidumistegevusest eristada, nimetati endeliste 
märkide vaatlemist 'observatsiooniks' ja teaduslik-tehnilist ennustuskunsti 'divinatsiooniks'. Alles hiliskeskajal asendusid õpetlaste poolt kasutatavad hilisantiiksed mõisted rahvakeelsete nimetustega 'nõid', 'ennustaja', 'unenägude seletaja', 'vaha pealt ennustaja', 'vaimude nägija' ${ }^{\prime 26} \mathrm{jm}$. Samas juurutati humanistide antiigivaimustuse tõttu antiigist pärit mõisteid veelgi lisaks või loodi nendega analoogseid sõnamoodustisi. $\underline{37}$

3. Kristlik maagiakriitika paigutab maagia muude Piibli esimese käsu vastu eksivate pattude hulka ning toetub lisaks sellele nõidust käsitlevatele reeglitele Vanas Testamendis, $\underline{\underline{38}}$ varakristlikule apologeetilisele kirjandusele ja varasematele konsiiliumi otsustele. ${ }^{39}$ Lisaks eeltooduile kasutatakse loodusteaduslikke ja ratsionalistlikke argumente, kusjuures need esinevad enamasti sõbralikult üksteise kõrval ning peavad tõendama kogu looduse allumist ühtsele kõikehaldavale jumalikule tahtele; näiteks võib tuua sellised autorid nagu Maximus von Turin (snd umbes 420), 40 Agobard von Lyon (799-849)1ㅜ või Hrabanus Maurus (780-

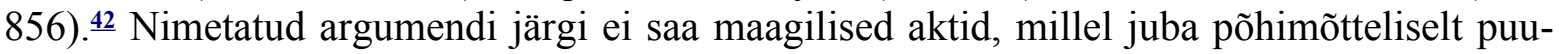
dub igasugune tõhusam toime, looduse vääramatut reeglipärasust häirida. Siiski omistatakse deemonitele võime aidata kaasa nõidumisel toimepandavate manipulatsioonide tulemusel vallanduvate mõjude tekitamisele intellektuaalsete ja tehniliste oskustega või petmise (illusioonide esilemanamise) teel. Kui varakeskajal domineeris veel illusiooniteooria, nagu see nähtub ka (tõenäoliselt Karolingi päritoluga) teosest Canon episcopi, ${ }^{43}$ siis hiliskeskajal öeldi sellest lahti ning väideti, et maagilised ilmutused on siiski reaalsed - eriti toonitati seda Heinrich Krameri «Nõiahaamris». ${ }^{44}$ Nimetatud muutusega kaasnes muuhulgas see, et Aquino Thomas lõi oma nägemuse Augustinuse õpetusest, mis käsitles lepingu sõlmimist deemonitega, $\underline{45}$ ning seda hakati süstemaatiliselt rakendama kõikide maagia ja ennustamise vormide juures. $\frac{46}{}$ Arutlustega uusplatonistliku demonoloogia kohta oli Augustinus pannud aluse kristliku deemonikäsitluse ja maagiateooria arengule - selle järgi on deemonite puhul tegemist langenud inglitega. Deemonid elavad õhus ning suudavad oma mittemateriaalse keha tõttu tungida inimese sisse ja manada tema silme ette pettekujutlusi. Nende vaimuloomusest tulenevad kehalised ja intellektuaalsed võimed aitavad neil toime panna kõikvõimalikke pettusi. Maagia leiutasid nad selleks, et inimesed neid jumalate asemel kummardama hakkaksid. Uusplatonistliku hüpoteesi, mille järgi deemoneid saab kosmilistest igitõmbejõududest lähtuvalt loodusseadustele lähedase iseenesestmõistetavusega käsutada, asendab Augustinus kujutelmaga märgilise lepingu sõlmimisest deemonitega. Sellele vastavalt pole tarvis deemoneid käsutada, vaid neid saab kindlate märkide abil soovitud tegevuseks üles kutsuda. Vahendeid, manipulatsioone jms, mis on käsiteldavad vastetena mõnele jumalale poolehoiu avaldamiseks toimepandud tegevusele, tõlgendab Augustinus märgisüsteemi elementidena, mida on võimalik kasutada deemonitega suhtlemisel ja lepingu sõlmimisel. Selleks, et inimene ja deemon saaksid suhelda nagu võrdne võrdsega, on vajalik iidne leping, milles on lahti seletatud maagiliste märkide tähendused. Sest nii nagu keel põhineb inimestevahelisel kokkuleppel ning selle kasutamine eeldab süsteemi kehtivuse vaikivat tunnustamist, baseerub ka maagiline kunst just kommunikatiivsel lepingul deemonitega. Keskajal käsitlesid Albertus Magnus (1200-1280), Aquino Thomas (1225-1274) ja Bonaventura (1221-1274) oma kommentaarides sententsidele ka lepingut kuradiga, toonitades selle usust taganemist esilekutsuvat iseloomu. $\frac{47}{}$ Aquino Thomas täiendas paktiõpetust selle võrra, et ta eristas selgelt väljendatud («pactum expressum») ja vaikivaid kokkuleppeid («pactum tacitum»). Sellega oli igasuguse maagilise ja üldse nõidumisega seotud tegevuse käsitlemine usust taganemisele osutava lepinguna inimese ja kuradi vahel teoreetiliselt põhjendatud. Järelikult võis usust taganejate (hereetikute, ketserite) jälitamiseks loodud inkvisitsiooniaparaati hakata rakendama ka nõidumises kahtlustatavate kui samuti «nõiasekti» kuuluvate isikute korralekutsumiseks. 
Siiski toonitati ka keskajal vajadust teha vahet filosoofilis-loodusteadusliku maagia ja demonistliku nõidumistegevuse vahel. Keskajale järgnenud perioodil tõsteti seda korduvalt esile. Albertus Magnus (umbes 1200-1280) eristas maage ennustajatest («aruspices», «divinatores») ja nõidujatest («necromantici», «incantatores») ja vaatles maagiat kui teadust asjade loomulikest põhjustest. $\underline{48}$ Wilhelm Auvergne'ist (umbes 1180-1249) võrdles magia naturalis't meditsiiniga, kuna seda maagialiiki kasutatakse samuti inimeste ravimise eesmärgil. $\underline{49}$ Roger Bacon (umbes 1120-1292) kuulutas maagia küll valeks ja illusoorseks, kuid oli ometi sunnitud tunnistama selle osalist tõelevastavust. ${ }^{\mathbf{5 0}}$ Siiski jäi spekulatiivse maagia traditsioon, mida keskajajärgsel perioodil täiendati mitmete kabalistlike elementidega, $\stackrel{51}{5}$ s.o püüd leida looduses jumala ilmutusi, õpetatud eliidi pärusmaaks; vastavatest autoritest võiks nimetada Valentin Wiegelit (1533-1588), Robert Fluddi (1574-1637), Johann Valentin Andreast (1586-1654), lisaks neile arvukaid roosiristlasi. Demonistliku maagiakäsitluse poole pealt saavutas kuradipaktiga seotud maagia («magia daemoniaca») nõiaprotsesside ümber käivate vaidluste tõttu aina enam avalikku tähelepanu. Jean Bodin (1529 või 1530-1596), Antonio Martínez Delrío (1551-1608) ja Benedictus Carpzov (1595-1666) pidasid kuradiga lepingu sõlmimise võimalust reaalseks, Johannes Weier (1515-1588), Balthasar Bekker (1634-1694) ja Christian Thomasius (1655-1728) aga väitsid vastupidist. $\underline{\mathbf{5 2}}$ Viimaks lõpetas 18. sajand nii õpetatud teoloogilis-filosoofilised kui õiguslikud vaidlused nõiduse ja nõidade olemuse üle ning sellega lõppes ka nõidade jälitamine. Moodsa loodusteaduse väljakujunemise protsessis mängis sellegipoolest teatud rolli ka spekulatiivne maagia. Looduse astroloogilisest ettemääratusest lähtuva maailmapildi asendamine matemaatilis-füüsikalise kausaalsuse kontseptsiooniga viis maagiliste mõjudega spekuleeriva (nii astroloogilise kui demonoloogilise) õpetuse hülgamiseni. Poeetiline käsitlus kosmilisel ligitõmbel põhineva maailmakorra struktuuridest ja keskustest pidi andma teed kõikvõimalike seoste empiirilisele tõestamisele ja objektiivsele jälgimisele. Tõeseks peeti ainult seda, mida oli võimalik konkreetsete mõõtmiste teel tõestada..$\underline{53}$

Kuna nõiajahi lakkamise järel kadus hirm maagilisest tegevusest lähtuva ohu ees, hakkas 18 . sajandist alates pead tõstma seeriaviisiline nõidusraamatute publitseerimine; maagiakirjanduse valda kuuluvatest vanadest tekstidest anti välja arvukaid esma- ja kordustrükke. Näiteks võib tuua ajaloolis-antikvaarse kallakuga tekstikogud Johann Christoph Adelungilt, $\underline{\mathbf{5 4}}$ Georg C. Horstiltt $\underline{55}$ ja J. Scheiblelt, $\underline{56}$ aga ka mitmeid kommertseesmärgilisi kordustrükke, mida tuntakse tänapäevani - «Moosese raamatud», «Claviculae Salomonis» jt. Tegemist on kogumikega, mis sisaldavad äärmiselt erineva päritoluga ja väga heterogeenseid tekste, tihti on tegemist fiktiivsete autorite (Mooses, Saalomon, Albertus Magnus, Doktor Faust) ja ilmumiskohtadega (Rooma, Veneetsia, Toleedo) ning salapäraste leiukohtadega (Vatikani kongides, kloostrite keldritesse kettidega kinni pandult), väidetakse, et teos on kirjutatud vere või fosforiga, see võib olla kinnitatud puna-musta surnupealuu kujulise pitseriga, köide on must ja lehtede lõikeäär punane. Raamatute sisu moodustavad palved, mälestussalmid, eepilised teated tervendamiste ja nõiduse kohta, kuradi väljakutsumise sõnad, nõiasõnad, salapitserid, amuletina toimivad vormelid ja maagilised vahendid. $\underline{57}$ Tänapäeva okultismiturul pakutakse nõidumisraamatute kõrval ka arvukaid maagilisi rekvisiite - amulette, talismane, pendleid ja nõiavitsu. Kuigi neid on täiendatud moodsate elementidega, neile on püütud kaalu anda pseudoteaduslike kinnitustega ja ühtlasi mitmeti moonutatud, võib siin siiski ära tunda õhtumaiste maagiatraditsioonide viimaseid võsusid. $\underline{58}$

Tõlkinud Reet Hiiemäe raamatust Dieter Harmening Zauberei im Abendland. Vom Anteil der Gelehrten am Wahn der Leute. 


\section{Märkused ja kirjandus}

1. F. Kluge. Etymologisches Wörterbuch der deutschen Sprache. Berlin ${ }^{201967, ~ v t ~ v e r b i ~ ' m o ̈ g e n ' ; ~ L . ~}$ Mackensen. Etymologisches Wörterbuch der deutschen Sprache. Stuttgart 1966, vt verbi 'magisch'.

2. T. Paracelsus. Werke, Bd. 5. W.-E. Peuckert (toim). Darmstadt 1976, 9; Järgneva kohta vrd M.-L. Thomsen \& D. Harmening \& Chr. Daxelmüller. Magie. Kindlers Enzyklopädie der Mensch. Bd. VI. Zürich 1983, lk 688-706; D. Harmening. Aberglaube. Samas, lk 707-718. D. Harmening. Superstitio. Überlieferungs- und theoriegeschichtliche Untersuchungen zur kirchlich-theologischen Aberglaubensliteratur des Mittelalters. Berlin 1979; D. Harmening. Aberglaube, Superstition. Lexikon des Mittelalters. Bd. 1. München, Zürich 1980, 29-32.

3. "genus sapientium et doctorum [---] in Persis», Cicero. De divinatione I, 23 (46), 41 (90 jj); De natura deorum I, 16 (43); De legibus II, 10 (26).

4. Js 44,25; 47,9.2; Jr 27,9; Hs 21,21; Tn 1,20; 2,2.10.27; 4,4; 5,11 .

5. Vrd J. Gnilka. Das Matthäusevangelium. I (Herders theologischer Kommentar zum Neuen Testament). Freiburg \& Basel \& Wien 1986, lk $35 \mathrm{jj}$.

6. K. Goldammer. Magie. Historisches Wörterbuch der Philosophie. Bd. 5. Darmstadt 1980, lk 632.

7. Empedokles von Akragas, Fragmente der Vorsokratiker, H. Diehls, W. Kranz (toim). (=VS), A 14.

8. Demokritos von Abdera, VS A 1.2.9.16.40.

9. Pythagoras von Samos, VS A 9.

10. Protagoras von Abdera, VS A 2.

11. Vrd Marcus Tullius Cicero (106-43 eKr). De finibus bonorum et malorum V, 87.

12. Aristoteles von Stageiros. Metaphysik XIII, 4, 1091 b 10.

13. Iamblichos von Chalkis. [De vita Pythagorica], 17.151.154. - Porphyrios von Tyros (243 kuni umbes 270 pKr). [Vita Pathagoreae], 6.41; [De abstinentia], Iv, 16.

14.Iamblichos. Über die Geheimlehren. Th. Hopfner (toim). (Bibliotheca Hermetica). Leipzig 21922, kordustrükk Schwarzenburg 1978.

15. Philon von Alexandreia. De specialibus legibus III, 100; Wörterbuch der Philosophie (nagu märkus 6), lk 632.

16. Järgneva kohta vrd Harmening. Magie (nagu märkus 2), lk $691 \mathrm{jj}$.

17. Proklos. Timaios-Kommentar IV. E. Diehl (toim), 1903-1906, kordustrükk 1974; Th. Hopfner. Griechisch-ägyptischer Offenbarungszauber (Studien zur Palaeographie und Papyruskunde 21, 23). Leipzig 1921, kordustrükk Amsterdam 1974, lk 19.

18. Harmening. Magie (nagu märkus 2), lk 692.

19. Picatrix. Araabia keelest tõlkinud H. Ritter ja M. Plessner (Studies of the Warburg Institute 27). London 1962.

20. Johannes Hartlieb. Das Buch aller verbotenen Künste, des Aberglaubens und der Zauberei. F. Eisermann, E. Graf (toim, tõlk). Ahlerstedt 1989, ptk 35, lk 48 (49).

21. L. Thorndike. The Writings of Peter of Abano. Baltimore 1944.

22. Vrd K. Arnold. Hexenglaube und Humanismus bei Johannes Trithemius. Der Hexenhammer. Entstehung und Umfeld des Malleus maleficarum von 1487 (Bayreuther Historische Kolloquien 2). Köln, Wien 1988, lk 217-240.

23. K. Biedermann. Handlexikon der magischen Künste von der Spätantike bis zum 19. Jahrhundert. Graz 1968, lk 376 jj.

24. Välja andnud ja kommenteerinud K. A. Nowotny. Graz 1967.

25.Järgnev on pärit: E. Cassirer. Individuum und Kosmos in der Philosophie der Renaissance (Studien der Bibliothek Warburg 10). Leipzig, Berlin 1927, kordustrükk21963, lk 103 jj. Vrd Harmening. Magie (nagu märkus 2), lk 694 jj.

26. Cassirer, samas, lk 105.

27. Opera omnia. I. Basel 1576, kordustrükk Turin 21962. Vrd P. O. Kristeller. The Philosophy of Marsilio Ficino. New York 1943.

28. Cassirer, Individuum (nagu märkus 25), lk $119 \mathrm{jj}$. 
29. Commentarius in Convivium Platonis de amore VI, 10; Opera omnia II (nagu märkus 27), 1348; Goldammer. Magie (nagu märkus 6), lk 633.

30. Vrd Harmening. Magie (nagu märkus 2), lk $695 \mathrm{jj}$.

31. Cassirer, Individuum (nagu märkus 25), lk 123.

32. Goldammer. Magie (nagu märkus 6), lk 632.

33. Harmening. Superstitio (nagu märkus 2), lk 302.

34. Samas, lk $219 \mathrm{jj}$.

35. Samas, pass.

36. Harmening. Aberglaube, Superstition (nagu märkus 2), $l k 31$.

37. F. Pfister. Zur Geschichte der technischen Ausdrücke der Wahrsagekünste. Oberdeutsche Zeitschrift für Volkskunde 7 (1933), lk 44-55.

38. Näiteks 2Ms 22,17; 3Ms 10,27; 5Ms 18: 9-12.

39. Harmening. Superstitio (nagu märkus 2), pass; Harmening. Aberglaube, Superstition (nagu märkus 2), lk $30 \mathrm{jj}$.

40. Homilia 100. De defectione lunae (I), ed. Patrologia latina. J. P. Migne (toim). Paris 1878 jj. (= PL), 57, lk 483-486.

41. Liber contra insulsam vulgi opinionem de grandine et tonitruis, ed. PL 104, lk 147-158.

42. Homilia 42. Contra eos qui in lunae defectu clamoribus se fatigant, ed. PL 110, lk 78-80.

43. Pärit: Regino von Prüm. Libri duo de synodalibus causis etc., ed. F. W. H. Wasserschleben. Leipzig 1840.

44. Harmening. Superstitio (nagu märkus 2), - «Nõiahaamri» kohta vrd P. Segl (toim). Der Hexenhammer (nagu märkus 22).

45. De doctrina christiana II, ed. Corpus scriptorum ecclesiasticorum latinorum 80, lk 33-78.

46. Thomas von Aquin. Summa theologiae II.II.92 sqq. - Järgneva kohta vrd Harmening. Aberglaube, Superstition (nagu märkus 2), lk 31 .

47. D. Harmening. «Hexe». Meyers Enzyklopädisches Lexikon. Bd. 10. Mannheim, Wien, Zürich 1974, lk 825.

48. Evangelium Matthei II, 1, ed. A. Borgnet. Opera omnia. 20. Paris 1893, lk 61.

49. De universo III, 2, 21 sq., ed. Opera omnia. I. Paris 1674, lk 1058.

50. Opus maius I, 14, ed. London 1773.

51. Chr. Daxelmüller. Magie (nagu märkus 2), lk 699-701.

52. Harmening. Hexe (nagu märkus 47), lk 825.

53. D. Harmening. Magietraditionen und Okkultkommerz. Journal für Geschichte 1985, H. 1, lk 38 jj.

54. Geschichte der menschlichen Narrheit, 1784.

55. Zauberbibliothek, 1821-1826.

56. Das Kloster, 1846.

57. Harmening. Magietraditionen (nagu märkus 53), lk 34.

58. D. Harmening (toim). Hexen heute. Magische Traditionen und neue Zutaten. (Quellen und Forschungen zur Europäischen Ethnologie 9). Würzburg 1991, pass. 